\title{
ESTADO/SOCIEDADE E O CONTROLE SOCIAL
}

\section{STATE/SOCIETY AND THE SOCIAL CONTROL}

\author{
Heloísa Helena Corrêa da Silva ${ }^{1}$
}

Luciana Paes Barreto Ferreira ${ }^{2}$

Maria Lúcia Barros ${ }^{3}$

\section{Resumo}

Este artigo tem por objetivo motivar teoricamente a discussão sobre o controle social, perpetrando um estudo da relação entre Estado e Sociedade, desde Hobbes, Locke e Rousseau, até os expoentes da doutrina marxiana. Aborda-se as discussões sobre o conceito de sociedade civil tanto na perspectiva marxiana quanto nas correntes liberais contemporâneas que têm implicações no debate e nas práticas sociais em torno do controle social.

Palavras-chave: Estado; Sociedade Civil; Controle Social.

\section{Abstract}

This article aims to motivate theoretically the discussion about the social control, through a study of the relation between State and Society, since Hobbes, Locke and Rousseau, until the exponents of the Marxian doctrine. It relates the controversies on the concept of civil society in the perspective marxiana and as much as contemporary liberal currents which have implications in the debate and in social practices around the social control.

Keywords: State; Civil Society; Social Control.

\footnotetext{
${ }^{1}$ Doutora em Serviço Social; Professora titular do curso de Serviço Social da Universidade Federal do Amazonas - UFAM. Av. André Araújo, no 63 - Apto. 101 - Adrianópolis. E-mail: heloisacorrea85@hotmail.com;

${ }^{2}$ Graduada em Serviço Social; Especialista em Antropologia da Saúde; Mestranda em Serviço Social e Sustentabilidade na Amazônia pela UFAM/ICHL. Rua Rio Jutaí, no. 1025 - Vieiralves. E-mail: lpbferreira@yahoo.com.br;

${ }^{3}$ Graduada em Normal Superior, Especialista em Pesquisas Educacionais pela UEA, Mestranda em Serviço Social e Sustentabilidade na Amazônia pela UFAM/ICHL. Rua A, quadra C, nº 19 - Conjunto Arthur Reis Parque 10. E-mail: mls barros@hotmail.com.
} 


\section{Introdução}

Do ponto de vista empírico, o controle social pode ser abordado sob diferentes perspectivas. Nas sociedades modernas e contemporâneas este debate está presente sob duas perspectivas: uma relacionada ao controle que o Estado exerce sobre os cidadãos; a outra, diz respeito ao controle que os cidadãos exercem sobre o Estado. Este debate integra o próprio processo de fundamentação do Estado Moderno. Na perspectiva que discute o Estado como um instrumento de controle sobre a sociedade, é importante destacar dois pensadores: Thomas Hobbes (1588 - 1679) e John Locke (1632 - 1704).

Contrapondo-se ao controle da sociedade, efetuado pelo Estado Liberal fez-se para os fins deste artigo uma incursão no pensamento dos autores marxianos, principalmente Karl Marx e Antonio Gramsci, nos quais se encontrou além da problematização das categorias aqui analisadas, a reflexão da práxis que apontam para outra forma de Estado e gestão participativa, sendo exemplares os casos da Comuna de Paris e dos Conselhos de Fábrica Italianos.

Sabe-se que esses autores influenciaram intelectuais e militantes brasileiros que direta ou indiretamente contribuíram para a formatação teórico/prática do controle social no Brasil a partir da participação social própria do contexto de redemocratização do país. Como exemplo desse processo pode-se citar a revitalização a partir dos meados dos anos 70 do século XX, pelo qual passou o Conselho Nacional de Saúde ${ }^{4}$.

Esse processo se horizontalizou para as demais áreas e ganhou espaço na sociedade civil brasileira enquanto controle social que tomou vulto no Brasil a partir do processo de estatuinte e constituinte na década de 1980 e, principalmente, com a institucionalização dos mecanismos de participação nas políticas públicas consagrados na Constituição de 1988 e nas leis orgânicas posteriores (Conselhos gestores e as Conferências setoriais).

Com o objetivo de traçar as raízes teóricas que dão suporte à discussão do controle social e às práticas neste âmbito, intencionando dar consistência teórica ao debate atual sobre o controle social que tem implicações nas práticas sociais, examinar-se-á as concepções de Estado e sociedade civil em Hobbes, Locke e Rousseau, cujos fundamentos estão guiados pela

\footnotetext{
${ }^{4}$ Sobre o assunto ver entre outros CARVALHO, A Conselhos de Saúde no Brasil: participação cidadã e controle social. Rio de Janeiro: FASE/IBM, 1995.
} 
razão abstrata. E, os expoentes da doutrina marxiana, cujos fundamentos estão na racionalidade do concreto 5 .

Este artigo está dividido em três partes: a primeira apresenta como se situa a relação entre o poder do Estado e os membros da sociedade nos jusnaturalistas. Na visão destes, que baseavam suas teorias principalmente na dicotomia estado de natureza / estado civil, a sociedade civil significava justamente este último, como sinônimo de estado politicamente organizado, em oposição à sociedade pré-estatal. Assim, a relação a ser examinada nestes pensadores para o estudo do controle social será entre o Estado (poder) e os membros da sociedade que são denominados súditos, comunidade e/ou povo.

A segunda parte aborda sobre as concepções de Estado e sociedade civil e da relação entre essas esferas em Marx e Gramsci, enfocando as diferenças entre eles quanto ao conceito de sociedade civil e quanto à função do Estado, implicando perspectivas díspares para a interpretação do controle social.

A terceira parte apresenta um debate sobre o conceito de sociedade civil nas correntes liberais contemporâneas que têm tido no cenário atual.

Concluindo, são realizadas algumas considerações sobre a influência das concepções da relação Estado/Sociedade nos referidos clássicos e nas correntes liberais contemporâneas para o debate e a prática em torno do controle social.

\section{O Estado em Hobbes, Locke e Rousseau}

Durante a Idade Média, o poder político era controlado pelos diversos senhores a feudais, que geralmente se submeteram ao imperador do Sacro Império e do Papa. Não haviam estados nacionais centralizados. Os filósofos clássicos romperam com a lei divina que definia as relações entre os homens predominantes na sociedade feudal e colocaram a história sob controle dos homens racionais, não mais em Deus, ainda que a razão dos homens fosse proveniente de Deus.

\footnotetext{
${ }^{5}$ O Concreto é o oposto ao Abstrato, embora ambos não existam em separado. Em Hegel e Marx o movimento do pensamento vai do abstrato ao concreto e se processa por escalas progressivas de concretização. Concreto e Abstrato fazem parte de uma totalidade, de uma unidade. O concreto é dado pelo pensamento e o abstrato é a percepção empírica enganosa da sociedade capitalista, para Marx o concreto deve entendido a partir do significado de devir em Hegel. Sobre essas categorias Ver:a Uma Contribuição para a crítica a economia política. O Capital. Livro I. Vol. I e II. Nova Cultura. São Paulo - SP. 1988 e Elementos fundamentales para la crítica de la economia política. 1857-1858.Buenos Aires.Siglo XXI, 1971.
} 


\section{DIVERS@!}

As modificações estruturais ocorridas modificaram o modo de produção feudal para o capitalista estabelecendo novas relações sociais, com a ascensão da classe burguesa e de seus novos valores. O surgimento do mercado baseado na compra e venda de mercadorias tendo o lucro como objetivo exigiu um ordenamento político e social compatível com o novo modo de produção. É este ordenamento que dá origem ao Estado Moderno. A centralização do poder foi uma necessidade para a expansão do sistema capitalista.

Outra concepção de homem passa a existir e com ela uma nova forma de organizar o Estado. Os teóricos precisavam explicar o que eram os indivíduos e porque lutavam uns contra os outros, além de precisarem oferecer teorias capazes de solucionar os conflitos e guerras sociais. Foram forçados a indagar sobre qual a origem da sociedade e da política (CHAUÍ, 1995). Iniciaram assim, a formulação de hipóteses e modelos teóricos destinados a captar a gênese da sociedade e do Estado.

Neste sentido, os pensadores da época tinham em comum a tentativa de compreender a sociedade por meio da razão científica derivada das ciências naturais, procurando uma conexão entre ela e ciência moral. Rompendo com o pensamento aristotélico-escolástico dominante no final da Idade Média ${ }^{6}$, no qual, o homem é um animal político que vive em grupo e é naturalmente social. A própria família já é uma espécie de sociedade (sociedade doméstica), onde já surge uma autoridade, a quem cabe estabelecer as regras.

O jusnaturalismo desprezou a abordagem histórica e desconsiderou a evolução cronológica das instituições construindo um modelo teórico ideal para explicar a origem da sociedade e o fundamento do Estado. Este modelo tinha por base: o estado de natureza e a sociedade (ou estado) civil fundado pelo Estado, através de um contrato social, por isso eram chamados contratualistas. O estado de natureza pode ser definido como o momento histórico anterior à formação de qualquer comunidade organizada, isto é, juridicamente ordenada pelo Estado.

Nos séculos XVII e XVIII a principal preocupação da filosofia política é o fundamento racional do poder soberano. Ou seja, o que se procura não resolver a questão da justiça, nem justificar o poder pela intervenção divina, mas colocar o problema da legitimidade do poder. É por isso que Hobbes, Locke e Rousseau têm o propósito de investigar a origem do Estado. Todos eles partem da hipótese do homem em estado de

\footnotetext{
${ }^{6}$ No modelo aristotélico a origem do Estado, enquanto polis ou cidade, é explicada a partir de uma construção histórica de etapas em que a humanidade teria passado das formas primitivas (família) às formas mais evoluídas de sociedade até chegar à sociedade perfeita que é o Estado. Neste sentido o significado originário de sociedade civil - a koinonéia politiké - é uma sociedade natural semelhante à família (BOBBIO, 1997:46).
} 


\section{DIVERS@!}

natureza e têm em comum o conceito de sociedade civil como sinônimo de sociedade política contraposta ao estado de natureza, em que o Estado é a instância que preserva a organização da sociedade a partir de um contrato social. Entretanto, mostram diferenças na concepção desta contraposição, no tipo de contrato regido pelo Estado e nas formas de controle social.

\subsection{Hobbes e o poder absoluto do Estado}

O filósofo inglês Hobbes (1979), defende e justifica a necessidade de um poder soberano e absoluto que garanta a vida e a propriedade dos indivíduos, pois no estado de natureza estas não têm garantias. Segundo ele, nas sociedades primitivas "o homem era o lobo do próprio homem", vivendo em constantes guerras e matanças, cada qual procurando garantir sua própria sobrevivência. Só havia uma solução para dar fim à brutalidade: entregar o poder a um só homem, que seria o rei, para que ele governasse todos os demais, eliminando a desordem e dando segurança a todos (COTRIM, 1987:134).

Para Hobbes a natureza humana é marcada por três características que tornam os homens competidores e potencialmente predadores: a primeira é a competição, leva os homens a atacar os outros em vista do lucro; a segunda é a desconfiança (por medida de segurança o homem precisa ver-nos outros uma ameaça constante), e a terceira característica é a glória, os homens, egoístas que são, buscam a reputação, o reconhecimento e a admiração dos outros (Leviatã, cap. XIII).

Neste caso, o Estado é a garantia para que os homens não se destruam, contudo, não basta um Estado produto de um pacto entre os homens, é preciso um Estado forte. Assim, os indivíduos para evitar a "guerra de todos contra todos", entregariam os seus direitos naturais, sua liberdade a propriedade a um só soberano - o Estado, que manteria o controle sobre todos.

A sociedade civil em Hobbes é antitética ao estado de natureza e só torna-se possível se submetida a um Estado absolutista com poder ilimitado, em que os homens tornam-se seus súditos com total subserviência. O Estado tem o poder absoluto de controlar os súditos que a este lhe entregou sua liberdade em troca da vida em segurança e da posse da propriedade. Neste contrato social estabelecido voluntariamente entre os homens, esses se tornam súditos submetidos ao controle do Estado portador de poder absoluto. Assim, pode-se inferir que na concepção de relação Estado/sociedade de Hobbes, o controle social é exclusivo do Estado absoluto - sem qualquer controle externo - sobre os membros da sociedade, que se tornam seus "súditos" (CORREIA, 2004:154). 


\subsection{Löcke e o individualismo liberal}

John Locke, filósofo inglês, considerado por muitos como o "Pai do Iluminismo", defende o individualismo liberal e critica o absolutismo. Para ele, o consentimento ${ }^{7}$ dos homens ao aceitarem o poder do corpo político instituído não retira seu direito de insurreição, caso haja necessidade de limitar o poder do governante. Além disso, o Parlamento se fortalece enquanto legítimo canal de representação da sociedade, e deve ter força suficiente para controlar o excesso dos Executivos.

No Ensaio sobre o Entendimento Humano, Locke afirma que a nossa mente é uma tábula rasa, sem nenhuma idéia. Tudo o que adquirimos é devido à experiência. Para ele nossas primeiras idéias vêm à mente através dos sentidos. Depois, combinando e associando as primeiras idéias simples, a mente forma idéias cada vez mais complexas. Em resumo, todo o conhecimento humano chega à nossa mente através dos sentidos e, depois, desenvolve-se pelo esforço da razão.

No estado de natureza de Löcke o trabalho era o fundamento originário da propriedade que se forma a partir da Vida, da Liberdade e dos Bens. Com o advento do dinheiro surgiu o comércio e uma nova forma de aquisição da propriedade, partir daí a propriedade reduz-se a bens, levando à concentração de riquezas, à desigualdade e ao risco dessa sofrer infração.

É a necessidade de impedir essas infrações à propriedade que leva os homens a se unirem e estabelecerem livremente entre si um contrato social cujo objetivo é a presença da mesma. (MELLO, 1993).

Ao contrário de Hobbes, Löcke não considera que o Estado de Natureza seja um estado de guerra, mas sim um estado pré-político, no qual já havia a propriedade privada e os homens conviviam em relativa paz. Essa sociedade pré-civil possuía direitos naturais que não poderiam ser desrespeitados quais sejam: a propriedade, a liberdade e a vida. Cada pessoa tinha o direito de se tornar juiz para julgar alguém que agisse contra esses princípios e é assim que, segundo Locke, a segurança civil poderia ver-se ameaçada.

Nenhum homem é capaz de alcançar seus próprios erros, mas são excessivamente rápidos em encontrar os alheios, por conseguinte, todos poderiam julgar-se inocentes, aos próprios olhos, e ainda assim ser culpados conforme o julgamento dos outros, principiando, então, o Estado de guerra.

\footnotetext{
${ }^{7}$ É uma das palavras chave na obra de Locke - consent, que permite compreender a origem e preservação da sociedade política ou civil do autor.
} 
Na visão de Löcke, os indivíduos que têm direitos políticos são todos proprietários. O Estado, que é composto pelo Legislativo e Executivo, tem o poder auferido por esses proprietários para a proteção de sua propriedade e de si mesmos. Para ele, o poder político em última instância está no "povo" que conserva ou destitui seus representantes no Poder Legislativo de acordo com seu desempenho na defesa da propriedade.

Em Löcke o controle social sobre o poder político do Estado é no sentido de limitar sua ação à garantia dos direitos naturais do indivíduo à propriedade, à vida e à liberdade através da vigilância ao cumprimento das leis e, quando essas forem desrespeitadas, através da resistência pelo uso da força para a dissolução deste poder e instituição de um novo que respeite os referidos direitos. Estão aqui as raízes do entendimento do controle social na doutrina do Estado liberal: controle sobre o poder político no sentido deste não interferir na economia, ou seja, para garantir a liberdade econômica. Em outras palavras, o poder político do Estado está limitado à garantia da liberdade individual à propriedade na perspectiva da liberdade econômica ilimitada.

\subsection{Rousseau e a democracia participativa}

Rousseau atribui a soberania ao "povo incorporado", isto é, ao povo enquanto corpo coletivo, capaz de decidir o que é melhor para o todo social. Com isso, desenvolve a concepção radical da democracia direta, em que o cidadão é ativo, participante, fazendo ele próprio as leis nas assembléias públicas.

Dentre suas obras, pode-se destacar $O$ Contrato Social, concluída em 1761 e publicada em 1762, Rousseau no Livro I desta obra ocupou-se em identificar a base "correta" para uma sociedade civil e de algumas principais características dessa sociedade. No Livro II Rousseau discute o governo, seu lugar no Estado, formas de governo, seus poderes e limites e expôs a tese de que o soberano deveria conduzir o Estado segundo a vontade geral de seu povo, sempre tendo em vista o atendimento do bem comum. Somente esse Estado, de bases democráticas, teria condições de oferecer a todos os cidadãos um regime de igualdade jurídica.

Tornou-se célebre como defensor da pequena burguesia e inspirador dos ideais que estiveram presentes na Revolução Francesa (COTRIM, 1987: 141). Denuncia a propriedade como uma das causas da origem da desigualdade e, ao desenvolver os conceitos de vontade geral e cidadania ativa, rejeita o elitismo da tradição burguesa do seu tempo. Além disso, as 


\section{DIVERS@!}

teorias contratualistas se baseiam em uma concepção individualista da sociedade, o que é típico do pensamento liberal.

Para ele a Democracia é constituída de três aspectos: a igualdade de participação; o político como espaço autônomo do agir humano (por considerar o interesse público como valor máximo da sociedade); a participação direta no poder.Dentro dessa visão de Rousseau encontra-se o ideal da democracia participativa que anima o difícil e complexo desafio do controle social.

Em Rousseau o governo é um comissário do povo e, a fiscalização pelo povo sobre as ações do governo, é a forma segura para evitar a usurpação e predomínio do interesse privado sobre o interesse público. Apesar de Rousseau ser jus naturalista, não foi defensor do liberalismo político tal qual Locke. Concebeu um Estado que deveria intervir para assegurar certo grau de igualdade. Para ele a finalidade de todos os sistemas de legislação se resumia na liberdade e na igualdade.

Rosseau, como os demais jus naturalistas, teve a preocupação com a criação de formulações teóricas que defendessem um Estado de direito, ou seja, um Estado cujo poder deve ser exercido dentro das normas jurídicas preestabelecidas. No entanto, diferente daqueles, seu Estado de direito teve como eixo um Estado democrático, em que o poder desse não só era limitado pelo povo, mas governado pela vontade geral. Teixeira (1998: 205) ressalta que a diferença da teoria de Estado de Rousseau da teoria do liberalismo clássico na sua vertente jus naturalista "salta aos olhos", pois enquanto a teoria dos direitos naturais busca motivos para limitar o poder do Estado frente ao abuso do poder, a teoria democrática de Rousseau considera que o único remédio para limitar tal poder é atribuí-lo à vontade geral que por sua natureza não pode abusar deste. Desta forma, pode-se afirmar que na perspectiva de Rousseau o povo controla o Estado, já que esse é expressão da vontade geral. O controle social é do povo sobre o Estado para a garantia da soberania popular.

É a partir da concepção de pacto social que se pode inferir a concepção de controle social em Hobbes, controle total do Estado absoluto sobre os súditos para acabar com a guerra de todos contra todos e para garantir a segurança e a posse da propriedade.Em Löcke, controle do "povo" - enquanto proprietários - sobre o Estado limitado seu poder à garantia dos direitos naturais (propriedade). E em Rousseau, controle total do povo - enquanto vontade geral - sobre o Estado, ou seja, o limite do poder do Estado está na sua essência de representar a vontade geral. 


\section{A Sociedade Civil e o Estado em Marx e Gramsci}

Com Hegel o conceito de sociedade civil deixa de identificar-se com o Estado, representando apenas um momento em sua formação. Ele inova ao conceituar a sociedade civil como sinônimo de sociedade pré-política, já delineando certa inversão do conceito empregado pelos jus naturalistas. De acordo com Bobbio (1997: 49), pela primeira vez, a sociedade civil não compreende mais o Estado na sua globalidade, mas representa apenas um momento no processo de formação do mesmo. Para ele, a sociedade civil de Hegel representa o primeiro momento de formação do Estado, ou seja, o Estado jurídico-administrativo, que tem a tarefa de regular relações externas. Já o Estado propriamente dito,

(...) representa o momento ético-político, cuja tarefa é realizar a adesão íntima do cidadão à totalidade de que faz parte (...) a distinção hegeliana entre sociedade civil e Estado representa a distinção entre um Estado inferior e um Estado superior (idem: 42).

Em seu sistema tricotômico, Hegel analisa que a sociedade civil aparece como momento intermediário entre a família e o Estado. Representa o momento em que a família, em função das necessidades que surgem, se dissolve nas classes sociais. Dessa forma, a sociedade civil, desprovida da organicidade, característica inerente ao Estado, é chamada por Hegel de "Estado externo" ou "Estado do Intelecto". No entanto, não é ainda em Hegel que se encontra a identificação da sociedade civil com a sociedade pré-estatal, no sentido que veio a tornar-se universal com Marx.

No pensamento de Hegel a sociedade civil é o momento que sucede a família como lugar de satisfação das necessidades. Para ele as classes sociais surgem com a dissolução da unidade familiar e com a oposição de diferentes interesses econômicos dos grupos que gera a anarquia generalizada que põe em risco a sobrevivência da sociedade. Para superar este estado de anarquia da sociedade civil surge o Estado como principio superior ordenador que faz prevalecer o interesse geral sobre os interesses particulares (TONET, 1990).

\subsection{Estado e Sociedade Civil em Marx}

Como bem ressalta Bobbio, o conceito encontrado em Hegel diferencia-se do encontrado no pensamento marx-engelsiano, sendo-lhe mais amplo e da mesma forma mais restrito, dependendo da forma de análise a ser utilizada. O conceito de sociedade civil de 
Marx parte da crítica ao idealismo hegeliano para elaborar os fundamentos da sua teoria da realidade social baseada nas condições materiais de existência.

A completa inversão do conceito opera-se, de fato, em Marx, para quem a sociedade civil coincide com a sociedade burguesa. Este autor estende seu sentido a toda a vida social pré-estatal, colocando-a no plano da estrutura (relações materiais e econômicas). Este trecho define claramente o pensamento de Marx:

A forma determinada de relações das forças produtivas existentes em todos os estágios históricos que se sucederam até hoje, e que por sua vez as determina, é a sociedade civil [...]. Já se pode ver aqui que essa sociedade civil é o verdadeiro centro, o teatro de toda história; e pode-se ver como é absurda a concepção da história até hoje corrente, que se limita às ações de líderes e de Estados e deixa de lado as relações reais [...]. A sociedade civil compreende todo o conjunto das relações materiais entre os indivíduos, no interior de um determinado grau de desenvolvimento das forças produtivas (in BOBBIO, 1982:31).

O pressuposto fundamental da sua teoria é que as condições materiais de existência constituem a base do todo social: "Vê-se já aqui que esta sociedade civil é a verdadeira fonte, o verdadeiro cenário de toda a história (...) A sociedade civil abrange todo intercâmbio material dos indivíduos, no interior de uma fase determinada de desenvolvimento das forças produtivas" (Marx e Engels: 1993: 52-53). Para ele, as condições materiais de uma sociedade são a base de sua estrutura social e da consciência humana.

Dessa forma, ocorreu uma completa inversão do conceito de sociedade civil, que deixa de significar o Estado em contraposição à sociedade pré-estatal, assumindo o sentido desta, em oposição ao Estado. Em Marx, a sociedade civil é definida em termos muito parecidos com os utilizados pelos jus naturalistas para definir o Estado de natureza.

Por fim, o Estado funciona como administrador dos conflitos advindos das relações sociais da sociedade, controlando o metabolismo social para manutenção da hegemonia da classe economicamente dominante. Nesta perspectiva, o controle social é entendido enquanto controle exclusivo do Estado sobre os membros da sociedade com a finalidade de garantir a aceitação da ordem do capital e a sua reprodução. 


\subsection{A relação Estado e Sociedade Civil em Gramsci}

Saliente-se, a importante contribuição de Gramsci a precisa análise de sociedade civil. Apesar de manter a dicotomia Sociedade Civil/Estado, Gramsci distancia-se de Marx ao deslocar a primeira esfera da estrutura para a da superestrutura, criando a dicotomia poder ideológico/poder político, ou seja, Gramsci concebe sociedade civil, não como estrutura, base material, mas como um momento da superestrutura, lugar em que se dá a formação do poder ideológico distinto do poder político, integrando uma noção ampliada de Estado.

Este autor, baseando-se no fato de não serem necessariamente as relações materiais e econômicas, mas sim a interpretação que se tem delas que determina a conduta política, entende a sociedade civil como sendo apenas um momento da superestrutura, particularmente o momento da hegemonia. Assim, colocando a sociedade civil como o momento do consenso contraposto ao da força, Gramsci prevê o fim do Estado pela reabsorção da sociedade política na sociedade civil.

O conceito de Estado ampliado em Gramsci procura dar conta teoricamente de um contexto em que havia uma crescente participação das massas na esfera política, resultando no que Coutinho (1994: 52) chamou de socialização da política, que se expressa na conquista do sufrágio universal, na criação de grandes partidos de massa, na ação efetiva de numerosos e potentes sindicatos profissionais e de classe. O poder do Estado se difunde no conjunto da sociedade civil, utilizando-se de aparelhos de consenso. Para Gramsci (apud CARNOY, 1990: 98), “a noção de Estado inclui elementos que também são comuns à noção de sociedade civil (neste sentido poder-se-ia dizer que o Estado $=$ sociedade política + sociedade civil. Em outras palavras a hegemonia garantida pela couraça da coerção)". Portanto, o Estado em Gramsci é ampliado por incorporar além da sociedade política a sociedade civil com seus aparelhos de hegemonia que mantêm o consenso.

Gramsci, ao identificar um Estado em sentido amplo, apresenta-o em duas esferas fundamentais: a sociedade política, "que se identifica com os aparelhos de coerção sob o controle das burocracias executivas e policial militar", e a sociedade civil, que é "o conjunto das organizações responsáveis pela elaboração e/ou difusão de ideologias" (COUTINHO, 1981). Para Gramsci, o equilíbrio entre a sociedade civil e a sociedade política seria dado pela hegemonia de um determinado grupo social sobre toda a sociedade, hegemonia esta que seria exercida pelas "organizações ditas privadas" (Igrejas, sindicatos, escolas, etc.). "Não há hegemonia ou direção político-ideológica se não existirem as organizações que compõem a 
sociedade civil e se os interesses desta última não estiverem representados no Estado e influenciando a formulação de políticas públicas" (COUTINHO, 1989).

Dentro do conceito gramsciano de Estado que se amplia com sua função de manutenção de consenso de uma classe sobre a outra através dos aparelhos privados da sociedade civil, pode-se situar na relação Estado e sociedade civil o controle social na disputa entre as classes para impor seus interesses na condução do Estado na busca da hegemonia.

O controle social seria movido pela contraditoriedade presente na sociedade civil, ora pendendo para a classe dominante, ora para as classes subalternas, a depender da correlação de forças entre essas.

O controle social na perspectiva das classes subalternas seria no sentido dessas ocuparem, cada vez mais, espaço na sociedade civil na busca de conquistar mais poder e formar consensos em torno de um projeto de classe contra-hegemônico. Nesta perspectiva de ampliação do Estado e de luta de classe que se estabelece na sociedade civil, surgem espaços para a fração da sociedade que representa as classes subalternas impor seus interesses e suas demandas ao Estado e este, a depender da correlação de forças existentes, incorporá-los ou não.

Vale ressaltar o aspecto contraditório em que se move o controle social na relação Estado/sociedade, pois enquanto a sociedade civil se constitui em campo de luta de classes na disputa pela imposição de projetos societários diferentes ao conjunto da sociedade, este controle poderá ser maior de uma classe ou de outra em determinados momentos, de acordo com a capacidade destas em formar consensos em torno do seu projeto e torná-lo hegemônico (CORREIA, 2004:165).

Assim, ao se utilizar a teoria de Gramsci para analisar a relação Estado/sociedade, pode-se qualificar a expressão controle social. Primeiro, tem que se levar em conta que a sociedade civil não é homogênea, nela circula interesses das classes antagônicas que compõe a estrutura social. Segundo, tem que se considerar a concepção ampliada de Estado que, na sua função de mantenedor da hegemonia da classe dominante, incorpora interesses das classes subalternas. É nesta luta para a incorporação desses interesses que se abre a possibilidade de as organizações das classes subalternas controlarem de alguma forma as ações do Estado e, consequentemente, influenciarem na alocação dos recursos públicos. 


\section{0 conceito liberal de sociedade civil e o gramsciano}

A concepção liberal de sociedade civil é a que tem prevalecido no debate contemporâneo. O que caracteriza essa concepção é uma dicotomia entre Estado e sociedade civil. Assim, a sociedade civil é tida, numa visão predominantemente política, sem articulação alguma com a base econômica, constituindo-se em um espaço homogêneo sem contradições de classe. Todos os interesses intrínsecos a ela se apresentam como universais, isentos do caráter de classe, e onde o ponto de partida e de chegada é sempre a liberdade e o benefício individual. Nessa perspectiva, a sociedade civil é o espaço do indivíduo, separada da esfera do Estado.

Gramsci não compartilha com a concepção de sociedade civil das teorias liberais, em que o ponto de partida e de chegada é sempre a liberdade e o benefício individual. Contrariamente, parte das necessidades concretas das classes subalternas e tem como fim a conquista de espaços hegemônicos para o seu projeto de sociedade. Na perspectiva liberal, a sociedade civil é o espaço do indivíduo, se separa da esfera do Estado. Gramsci não separa a sociedade civil da política - partes do todo denominado "Estado Ampliado", mas estabelece uma relação dialética entre essas esferas.

O conceito liberal não tem nada a ver com o conceito de sociedade civil em Gramsci que tem uma dimensão claramente política enquanto espaço de luta de classe pela hegemonia e pela conquista do poder político por parte das classes subalternas (COUTNHO, 2002).

$\mathrm{Na}$ concepção de Gramsci, na sociedade civil estão presentes tanto os interesses das classes dominantes através de seus aparelhos privados de hegemonia (meios de comunicação, associações e etc.) como os interesses das classes subalternas na busca de construir sua hegemonia.

Apesar das numeross análises a que o conceito de sociedae civil gramisciniano foi submetido nos últimos anos, ainda não se esgotou o debate acerca desse conceito e sua importância superestrutural,que se encontra em um dos textos dos Cadernos (1975).

Tratar a sociedade civil como homogênea é desconectá-la das relações sociais de produção, do todo social. Pois, são as contradições que emanam desta base econômica, que se expressam e se confrontam na sociedade civil. Assim, pode-se afirmar que a heterogeneidade dos interesses que compõem a sociedade civil é reflexo da mesma heterogeneidade das classes que compõem as relações sociais de produção. 


\section{DIVERS@!}

Quanto ao entendimento da expressão controle social dentro da perspectiva liberal contemporânea, este é apresentado como controle da sociedade civil - que é considerada homogênea sem conflitos de classe e portadora de interesses universais - sobre o Estado que é neutro e está acima das classes sociais. Enquanto na perspectiva gramsciana este controle se refere à possibilidade de os setores da sociedade civil que representam os interesses das classes subalternas obterem algum controle sobre o Estado impondo seu projeto societário contra-hegemônico.

\section{Considerações finais}

A partir dos dados expostos, vê-se que o conceito de "sociedade civil" e a qualificação de seus atos, é algo que sempre coube aos maiores pensadores. Todas as concepções da relação entre Estado e sociedade apresentada, desde a dos jusnaturalistas (Estado x súditos, comunidade ou povo) com suas particularidades em cada teórico, até as marxistas com suas diferenças entre seus representantes e as liberais recentes, têm influenciado nas práticas e abordagens do controle social na atualidade.

O controle social tanto é empregado para designar o controle do Estado sobre os membros da sociedade, quanto para designar o controle destes sobre as ações do Estado no sentido deste incorporar suas demandas. Entre os clássicos analisados situam-se, de forma diferente, nessa primeira acepção Hobbes, que na perspectiva jusnaturalista, é defensor de um Estado absoluto e da submissão total dos membros da sociedade ao mesmo para garantir a vida e a propriedade, dirimir conflitos e manter a ordem; e Marx, que na perspectiva classista, observou na realidade de sua época o domínio sobre toda a sociedade. Para algumas análises marxistas contemporâneas, o Estado tem controlado o conjunto da sociedade em favor dos interesses da classe dominante através da implementação de políticas sociais para amenizar os conflitos de classe e manter o seu domínio.

Na segunda definição situam-se, de maneira bem diferenciada, Löcke e Rousseau. Em Locke encontram-se as origens do controle dos membros da sociedade sobre o poder político, quando este pensador concedeu ao povo o poder de resistência aos governantes que desrespeitassem os direitos naturais. Dentro do primado do liberalismo defende a subordinação do Estado aos interesses do indivíduo. O controle social é do "povo" sobre o 
Estado, impondo limites ao poder político no sentido deste não interferir na liberdade da posse individual, ou seja, na liberdade de expansão do poder econômico.

Em Rousseau, o governo é um comissário do povo e a fiscalização pelo povo sobre as ações do governo, é a forma segura para evitar a usurpação e predomínio do interesse privado sobre o interesse público. Ele idealizou um Estado totalmente controlado pelo povo por ser expressão deste. No arcabouço teórico de Rousseau estão as raízes da soberania popular e do controle social enquanto controle da sociedade sobre o Estado, defendendo o interesse público sobre o interesse privado nos negócios públicos.

Em Gramsci, adepto da corrente marxista, o controle social é contraditório, podendo ser de uma classe ou de outra, pois a sociedade civil enquanto momento do Estado é um espaço de luta de classes pela disputa de poder. É a partir da sua concepção de Estado Ampliado quando incorpora as demandas das classes subalternas, que se abre a possibilidade de o Estado ser controlado por essas classes, a depender da correlação de forças existentes na sociedade civil.

O controle social poderá acontecer via políticas públicas, pois através delas o Estado controla a sociedade, ao tempo que é controlado por essa ao incorporar suas demandas. Desta forma, o controle social na perspectiva das classes subalternas visa a atuação de setores da sociedade civil organizada que as representam na gestão das políticas públicas no sentido de controlá-las para que estas atendam, cada vez mais, às demandas sociais e aos interesses dessas classes. Neste sentido, o controle social envolve a capacidade que as classes subalternas, em luta na sociedade civil, têm para interferir na gestão pública, orientando as ações do Estado e os gastos estatais na direção dos interesses desta classe tendo em vista a construção de sua hegemonia.

A partir do referencial teórico de Gramsci em que não existe uma oposição entre Estado e sociedade civil, mas uma relação orgânica, o controle social acontece na disputa entre essas classes pela hegemonia na sociedade civil e no Estado. Assim, o controle social é contraditório - ora é de uma classe, ora é de outra - está balizado pela referida correlação de forças.

Assim, conclui-se que na perspectiva gramsciana o controle social deverá ser entendido dentro da articulação dialética entre o Estado ampliado e a sociedade civil comporta por interesses de classes diferentes, e deverá se dar na perspectiva da defesa dos interesses das classes subalternas e de construção de resistência às tendências do uso do fundo público para o financiamento da reprodução do capital em detrimento do financiamento da reprodução do 


\section{DIVERS@!}

trabalho. Controle social norteado por um projeto societário das classes subalternas e pela busca da construção de uma cultura política da contra-hegemonia.

\section{Referências}

BOBBIO, N. Estado, Governo e Sociedade: Para uma teoria geral da política. Rio de Janeiro: Paz e Terra, 1997.

BOBBIO, N. Dicionário de Política. Brasília. Editora UNB, 1999.

BOBBIO, N. O Conceito de Sociedade Civil. Trad. Marco Aurélio Nogueira. Rio de Janeiro: Graal, 1982.

CARNOY, M. Estado e teoria política. 3. ed. Campinas: Papirus, 1990.

CARVALHO, A. Conselhos de Saúde no Brasil: participação cidadã e controle social. Rio de Janeiro: FASE/IBM, 1995.

CHAUÍ, M. Convite à Filosofia. 3. ed. São Paulo: Ática, 1995.

CORREIA, M. V. A relação Estado/Sociedade e o controle social: fundamentos para o debate. Serviço Social \& Sociedade, n. 77, São Paulo, Cortez, 2004.

COUTINHO, C. N. Gramsci. Porto Alegre: LPM, 1981.

COUTINHO, C. N. Um estudo sobre seu pensamento político. Rio de Janeiro, Campus, 1989.

COUTINHO, C. N. Marxismo e política: a dualidade de poderes e outros ensaios. São Paulo, Cortez, 1994.

COUTINHO, C. N. Gramsci e a sociedade civil. Disponível em: <http://www.gramsci.org >, 2002. 


\section{DIVERS@!}

COTRIM, G. Fundamentos da filosofia: para uma geração consciente. 2. ed. São Paulo: Saraiva, 1987.

GRAMISCI, A. Quaderni del Carcere. Einaudi, Torino, 1975.

HEGEL, G. W. F. Ciencia de la Lógica. Tomo I. Buenos Aires. Librerie Achete S/A.1956.

HOBBES, T. Leviatã. 2. ed. Trad. João Paulo Monteiro e Maria Beatriz Nizza da Silva. São Paulo, Abril Cultural, 1979 (col. Os Pensadores).

LÖCKE, J. Two Treatises of Government. New York. Hafnner Publishing Co. 1961.

MARX, K.; ENGELS, F. A ideologia alemã. 9. ed. Trad. José Carlos Bruni e Marco Aurélio Nogueira. São Paulo: Hucitec, 1993.

MARX, K. O Capital. Livro I. Vol. I e II. Nova Cultura. São Paulo - SP. 1988.

MARX, K. Elementos fundamentales para la crítica de la economia política. 1857-1858. Buenos Aires.Siglo XXI, 1971.

MELLO, L. I. A. John Locke e o individualismo liberal. In: Os clássicos da política: Maquiavel, Hobbes, Löcke, Montesquieu, Rousseau, "O Federalista”. Organizador WEFFORT, Francisco Corrêa.4 .ed., v. 1. São Paulo, Ática, 1993.

TEIXEIRA, F. J. S. O neoliberalismo em debate. In: TEIXEIRA, Francisco José Soares \& OLIVEIRA, Manfredo Araújo de. (orgs.). Neoliberalismo e reestruturação produtiva: as novas determinações do mundo do trabalho. 2. ed. São Paulo/Fortaleza, Cortez/Universidade Estadual do Ceará, 1998.

TONET, I. Sobre o conceito de sociedade civil. Serviço Social \& Sociedade, n. 32, São Paulo, Cortez, 1990. 